\title{
Identifikasi Letak Cracks pada Bidang Longsor Menggunakan Metode Resistivitas 2D
}

\author{
Arin Dwi Agustin, Widya Utama dan Juan Pandu Gya Nur Rochman \\ Teknik Geofisika, Fakultas Teknik Sipil dan Perencanaan, Institut Teknologi Sepuluh Nopember (ITS) \\ Jl. Arief Rahman Hakim, Surabaya 60111 Indonesia \\ e-mail:widya@geofisika.its.ac.id
}

\begin{abstract}
Abstrak-Bencana tanah longsor merupakan bancana alam yang sering terjadi di Indonesia, terutama pada daerah yang memiliki kelerengan yang cukup curam. Berdasarkan peta gerakan tanah Kab. Blitar yang dikeluarkan oleh Kementrian ESDM pada bulan Oktober 2016 [5], kawasan penelitian yang berada di Kecamatan Selorejo memiliki potensi gerakan tanah menengah. Salah satu faktor yamg mempengaruhi kestabilan lereng adalah adanya cracks yang terbentuk dibawah permukaan. Ketika cracks dalam lereng terinfiltrasi oleh air hujan, maka akan menjadi proses water prressure built up pada lereng yang menyebabkan lereng tidak stabil. Salah satu metode geofisika yang dapat mendeteksi keberadaan cracks adalah metode geolistrik. Dengan metode ini akan diketahui daerah yang memiliki kandungan air tinggi yang ditunjukkan dengan nilai resistivitas yang rendah. Pada penelitian ini, dilakukan pengukuran tentang perilaku cracks pada lereng ketika sebelum dan sesudah hujan. Setelah dilakukan pengukuran terhadap 6 lintasan, didapatkan hasil bahwa cracks memiliki rentang nilai resistivitas sekitar 0.1 - $1.6 \Omega \mathrm{m}$ dengan kedalam sekitar 3 meter.
\end{abstract}

Kata Kunci-cracks, longsor, resistivitas

\section{PENDAHULUAN}

$\mathrm{T}$ ANAH Tanah longsor adalah suatu gerakan menuruni lereng oleh massa tanah dan atau batuan penyusun lereng. Pergerakan tanah dapat diketahui dengan tanda - tanda seperti munculnya retak tarik dan kerutan di permukaan lereng, miringnya pepohonan, hilangnya kelurusan fondasi bangunan dan lainnya [1].

Kabupaten Blitar merupakan salah satu kawasan di Jawa Timur dengan kondisi geologi berupa pegunungan vulkanik pada bagian utara dan bagian selatan merupakan dataran rendah (PPID Kab. Blitar). Salah satu Kecamatan yang rawan tanah longsor merupakan Kecamatan Selorejo dengan tingkat gerakan tanah menengah (Pusat Vulkanologi dan Mitigasi Bencana Geologi, 2016).

Salah satu penyebab terjadinya peristiwa tanah longsor adalah adanya retakan (cracks) dalam tanah. Dengan adanya cracks, air hujan yang masuk akan menambah beban lereng sehingga mempercepat proses terjadniya bencana tanah longsor.

Metode gofisika yang mampu mendeteksi adanya cracks adalah metode resistivitas, dimana dengan metode ini zona yang memiliki kandungan air jenuh dapat dijadikan acuan tentang adanya cracks dalam tanah.

\section{DASAR TEORI}

\section{A. Geologi Regional}

Wilayah Kabupaten Blitar terbagi menjadi dua wilayah yaitu wilayah Utara dann Selatan yang dipisahkan oleh Sungai Brantas. Pada wilayah selatan, memiliki topografi sebagian besar wilayah perbukitan dan pada daerah sekitar aliran sungai Brantas memiliki topografi sedikit landai. Daerah peneliian termasuk dalam wilayah Utara, dimana kemiringan lereng $2 \%$ $40 \%$ dengan kondisi wilayah bergelombang sampai dengan berbukit, hal ini dikarenakan pada wilayah utara merupakan bagian dari Gunung Kelud dan Gunung Butak (RPJMD Kabupaten Blitar 2011 - 2016)

Daerah penelitian berada di Dusun Dawung, Desa Olak Alen, Kecamatan Selorejo Blitar. Berdasarkan [4], daerah penelitian termasuk dalam formasi endapan vulkanik gunung Butak dengan jenis batuan penyusun lava, breksi gunungapi, tuff breksi dan tuff pasiran.

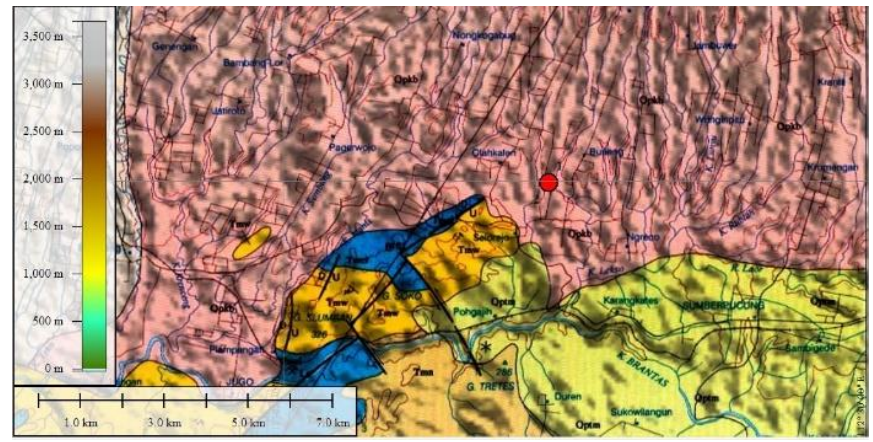

Gambar 1. Geologi daerah penelitian yang ditunjukkan titik berwarna merah

\section{B. Metode Resistivitas}

Metode geolistrik resistivitas merupakan metode geolistrik yang mempelajari sifat resistivitas (tahanan jenis) listrik dari lapisan batuan di dalam bumi. Prinsip dasar yang digunakan pada metode ini adalah Hukum Ohm. dimana beda potensial pada ujung penghantar sama dengan hasil kali resistansi (R) dan kuat arus (I). Resistansi (R) merupakan besarnya nilai hambatan suatu medium. Sedangkan resistivitas adalah kemampuan suatu medium untuk menghambat arus listrik yang mengalir. Besarnya nilai resistivitas inilah yang digunakan untuk mengetahui kondisi bawah permukaan. Untuk mengetahui besarnya nilai resistivitas yang bergantung pada konfigurasi 
yang dilakukan saat pengukuran, dapat dirumuskan sebagai berikut ini :

$\rho=\frac{2 \pi \rho V_{M N}}{I}\left\{\left[\frac{1}{A M}-\frac{1}{M B}\right]-\left[\frac{1}{A N}-\frac{1}{N B}\right]\right\}^{-1}$

Pada penelitian ini, digunakan konfigurasi Wenner Schlumberger yang memiliki urutan elektroda seperti berikut ini :

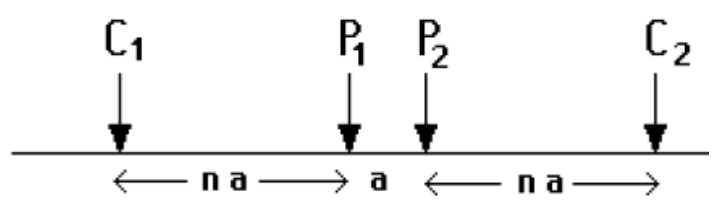

Gambar 2 Konfigurasi wenner- schlumberger (Loke,2000) [2].

\section{Tanah Longsor dan Cracks}

Menurut [6] istilah longsoran digunakan untuk seluruh jenis gerakan tanah. Sedangkan menurut Hardiyatmo (2012), Longsor adalah gerakan massa batuan induk dan lapisanlapisan tanah pada bagian lereng atas dengan kemiringan landai sampai sangat curam ke arah kaki lereng sebagian akibat terlampauinya keseimbangan daya tahan lerengnya. Pergerakan tanah dapat diketahui dengan tanda - tanda seperti munculnya retak tarik dan kerutan di permukaan lereng, miringnya pepohonan, hilangnya kelurusan fondasi bangunan dan lainnya.

Cracks (retakan) adalah suatu bidang diskontinuitas pada batuan yang dapat diinterpretasikan sebagai hasil dari suatu deformasi. Menurut [3] cracks merupakan salah satu faktor yang berpengaruh dalam kestabilan lereng. Dengan adanya limpasan aiar yang mengisi celah maka dapat mengubah lereng akibat perbedaan karakteristik dan kekuatan geser tanah.

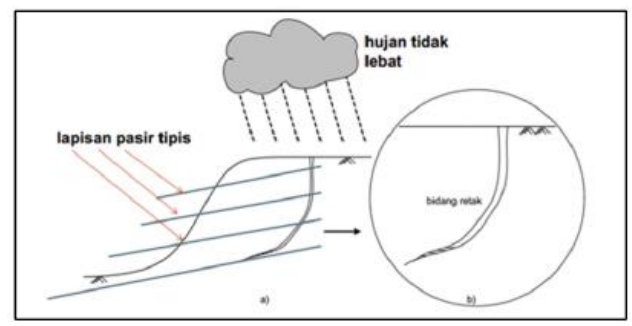

Gambar 3. Proses rembesan air hujan pada lereng

Lokasi penelitian ini berada di Dusun Dawung, Desa Olak Alen, Kecamatan Selorejo, Blitar. Adapun metodologi yang dilakukan adalah sebagai berikut :

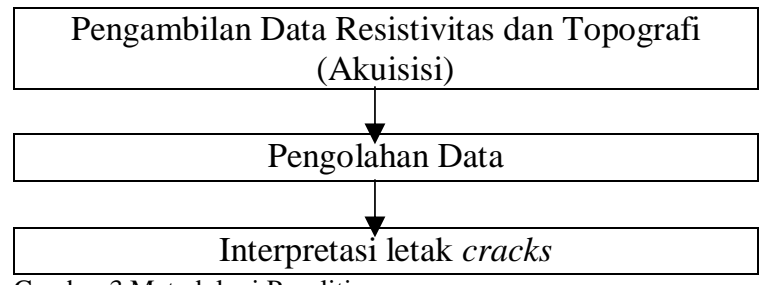

Gambar 3 Metodologi Penelitian
Tahap akuisis bertujuan untuk melakukan pengambilan data resistivitas bawah permukaan. Untuk mengetahui kondisi topografi daerah setempat, dilakukan pengambilan data topografi dengan teodolit. Pengambilan data dilakukan pada 6 lintasan yang sejajar maupun tegak lurus dengan arah longsoran yang berarah Timur -barat.

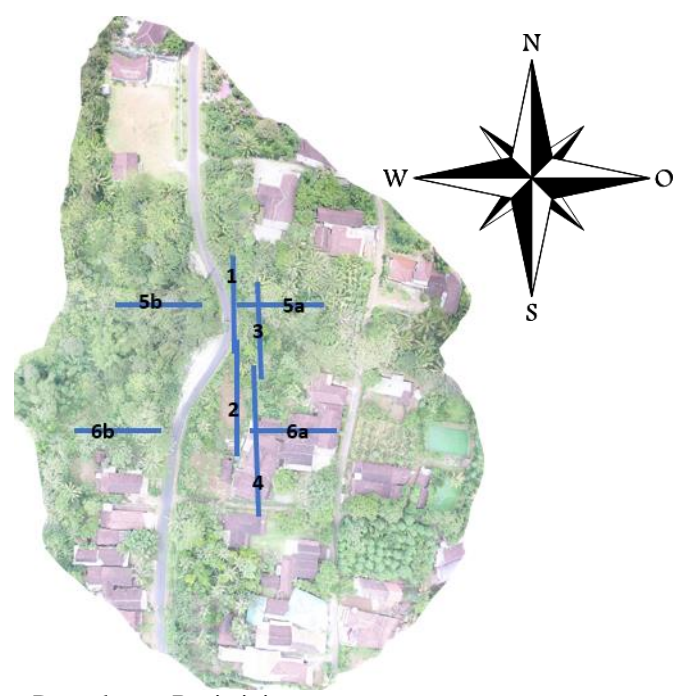

Gambar 3 Lintasan Pengukuran Resistivitas

Setelah dilakukan proses akuisisi, maka dilakukan pengolahan data resistivitas untuk selanjutnya dilakukan interpretasi letak cracks dari hasil penampang resistivitas.

\section{HASIL DAN PEMBAHASAN}

\section{A. Analisis Letak Cracks Pada Line 1}

Line 1 memiliki arah lintasan Utara - Selatan dengan panjang bentangan adalah 30 meter spasi 1 meter. Hasil penampang resistivitas line 1 akan ditunjukkan pada gambar 5

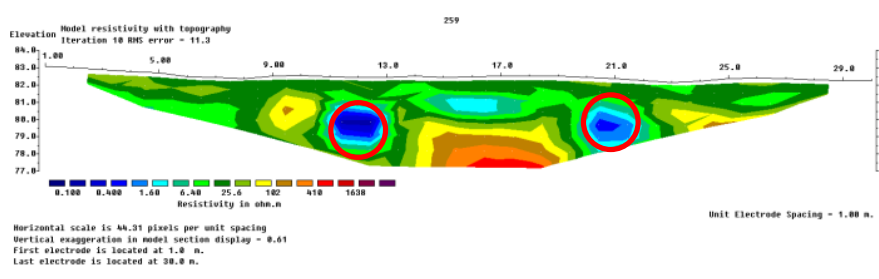

Gambar 5 Penampang resistivitas line 1

Pada penampang ini, diketahui bahwa cracks berada pada jarak bentangan $12-13$ meter dengan kedalaman $2-3$ meter dibawah permukaan. Letak cracks ditunjukkan oleh nilai resistivitas yang rendah yaitu sekitar $0.1-1.6 \Omega \mathrm{m}$. Hal ini dikarenakan pada daerah tersebut memiliki kandungan air yang cukup tinggi. Air tersebut tersimpan pada retakan yang telah terbentuk sebelumnya.

Pada line 5b memiliki topografi yang cukup curam. Lintasan $5 \mathrm{~b}$ inilah yang pernah terjadi peristiwa longsoran sebanyak dua kali. Berikut adalah penampang resistivitas untuk line $5 \mathrm{~b}$ : 


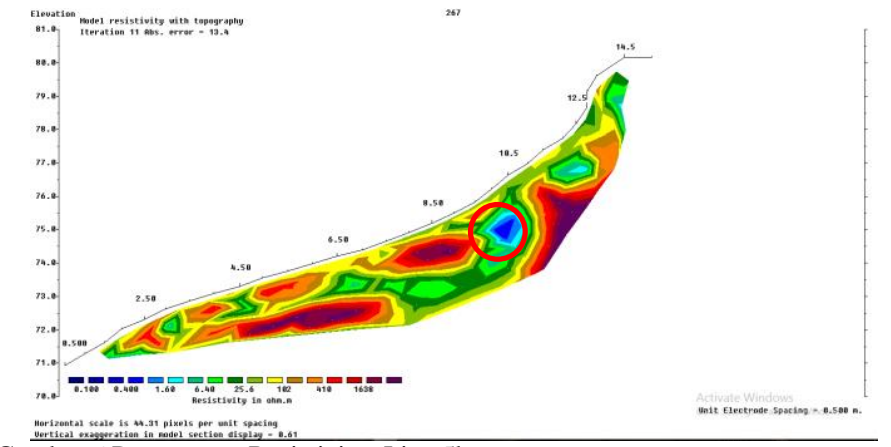

Gambar 6 Penampang Resistivitas Line 5b

Lintasan 5 b memiliki bentangan maksimal 15 meter dengan spasi elektroda adalah 0.5 meter. Pada penampang tersebut, letak cracks terletak pada bentangan $9-9.5$ meter dan pada kedalaman 0.5 sampai 1 meter. nilai resistivitas untuk daerah yang memiliki cracks yaitu $0.1-1.6 \Omega \mathrm{m}$. Litologi yang mendominasi pada daerah ini adalah lempung. Sehingga cracks diindikasikan terletak pada lapisan lempung yang tersaturasi air.

\section{KESIMPULAN/RINGKASAN}

Berdasarkan penelitian yang telah dilakukan dapat diambil kesimpulan bahwa berdasarkan data resistivitas hasil pengukuran, letak cracks pada line 1 yaitu pada bentangan 12 13 meter dengan kedalaman $2-3$ meter. sedangkan untuk line 5 b terletak pada entangan $9-9.5$ meter dan pada kedalaman 0.5 sampai 1 meter. Letak cracks tergantung pada daerah yang mampu menyimpan air dengan litologi yang mendominasi adalah lempung. Saran untuk penelitian selanjutnya adalah perlunya pemetaan yang lebih rinci tentang keberadaan cracks yang sudah terlihat dipermukaan. Selain itu, spasi pengukuran sebaiknya lebih kecil agar mendapat pola aliran cracks lebih detail dan penggabungan dengan data bor untuk mendapatkan hasil yang lebih akurat.

\section{DAFTAR PUSTAKA}

[1] Hardiyatmo, H.C., “ Penanganan Tanah Longsor dan Erosi”, Gadjah Mada University Press, Yogyakarta, 2012

[2] Loke, M.H, “ Electrical imaging surveys for environmental and engineering studies", 2000

[3] Eko Andi Suryo,"Application of Electrical Resistivity Method to Detect Deep Cracks in Unsaturated Residual Soil Slope",Proceeding of APUNSAT 2011 : 5th Asia - Pasific Conference on Unsaturated Soils,2011

[4] Peta Geologi Indonesia lembar Blitar, 1992

[5] Peta Wilayah potensi gerakan tanah di provinsi jawa timur bulan september 2016. Kementerian energi dan sumber daya mineral Republik Indonesia

[6] Vernes,"Slope movement types and processes", In: Schuster RL, Krizek RJ (eds) Landslides, analysis and control, special report 176: Transportation research board,National Academy of Sciences, Washington, DC., pp. 11,1978 